\title{
$\begin{array}{ll}\text { Research Square } & \text { Preprints are preliminary reports that have not undergone peer review. } \\ \text { They should not be considered conclusive, used to inform clinical practice, }\end{array}$ or referenced by the media as validated information. \\ Enhanced Patterned Cocatalyst Ti02/Fe203 Photoanodes for Water-Splitting
}

\section{Wei-Hsuan Hung}

Institute of Material Science and Engineering, National Central University

\section{Yung-Jen Teng}

Department of Material Science and Engineering, Feng Chia University

Chuan-Ming Tseng ( $\nabla$ cmtseng@mail.mcut.edu.tw)

Ming Chi University of Technology https://orcid.org/0000-0003-1834-7726

Thi Thai Hien Nguyen

Institute of Material Science and Engineering, National Central University

\section{Nano Express}

Keywords: bimetallic oxide, periodic pattern, hot-pressing process, water splitting

Posted Date: January 26th, 2021

DOl: https://doi.org/10.21203/rs.3.rs-152583/v1

License: (9) This work is licensed under a Creative Commons Attribution 4.0 International License. Read Full License 
Chuan-Ming Tseng, Ph.D.

$+886-2-29089899 \# 4402$

Assistant Professor

+866-2-29084091 FAX

Department of Materials Engineering

cmtseng@mail.mcut.edu.tw

Editor of Nanoscale Research Letters

January 20, 2021

Dear Editors:

Please find our submission "Enhanced Patterned Cocatalyst $\mathrm{TiO}_{2} / \mathrm{Fe}_{2} \mathrm{O}_{3}$ Photoanodes for Water-splitting".

In this study, we used a hot-pressing process to enhance the photocatalytic properties of $\mathrm{TiO}_{2} / \mathrm{Fe}_{2} \mathrm{O}_{3}$ bimetallic oxide with a periodic patterned structure on the surface to increase photon absorption for photocatalysis in the oxygen evolution reaction (OER) for water splitting. The hot-pressed samples show that combining the two metal oxides improves the absorption band edge of the electrode at different wavelengths. The patterned structure obtained using the hot-pressing process successfully improves photon absorption, resulting in a twofold enhancement compared with a flat surface electrode.

The following findings are of high importance to the basic science of water splitting and will have an enormous impact on the water splitting economy's future.

(1) $\mathrm{TiO}_{2} / \mathrm{Fe}_{2} \mathrm{O}_{3}$ bimetallic oxide is an excellent alternative of photocatalyst over the noble metals used.

(2) Hot-pressing process is a simple process used to enhance the photocatalyst's properties by patterning a periodic structure on the surface, which is beneficial for the OER reaction.

(3) We successfully imprinted a uniformly patterned on the surface of $\mathrm{TiO}_{2} / \mathrm{Fe}_{2} \mathrm{O}_{3}$ photoanodes, which improves the light absorption over a broad range of 400-600 $\mathrm{nm}$.

(4) This study demonstrated a two-fold improvement compared with the $\mathrm{TiO}_{2} / \mathrm{Fe}_{2} \mathrm{O}_{3}$ sample produced without using the hot-pressing process and seven-fold current improvement compared with $\mathrm{TiO}_{2}$ only.

We'd like to recommend the following experts to review this work.

1) Yu-Lun Chueh, National Tsing Hua University, ylchueh@mx.nthu.edu.tw

2) Jyh Ming Wu, National Tsing Hua University, wujm@mx.nthu.edu.tw

3) Johnny C. Ho, City University of Hong Kong, johnnyho@ cityu.edu.hk

4) Dongdong Li, Shanghai Advanced Research Institute, Chinese Academy of Sciences, lidd@sari.ac.cn

5) Zhiyong Fan, The Hong Kong University of Science And Technology, eezfan@ust.hk

Sincerely,

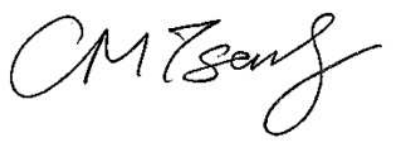

CHUAN-Ming TSENG 


\title{
Enhanced Patterned Cocatalyst $\mathrm{TiO}_{2} / \mathrm{Fe}_{2} \mathrm{O}_{3}$ Photoanodes for Water-splitting
}

Wei-Hsuan Hung ${ }^{1, *}$, Yung-Jen Teng ${ }^{2}$, Chuan-Ming Tseng ${ }^{3,4}, *$, Thi Thai Hien Nguyen ${ }^{1}$

${ }^{1}$ Institute of Materials Science and Engineering, National Central University, No. 300 Jhong-da Rd., Jhongli City 320, Taoyuan County, Taiwan, ROC.

${ }^{2}$ Department of Materials Science and Engineering, Feng Chia University, Taichung 407, Taiwan, ROC.

${ }^{3}$ Department of Materials Engineering, Ming Chi University of Technology, New Taipei City, 24301, Taiwan, ROC.

${ }^{4}$ Center for Plasma and Thin Film Technologies, Ming Chi University of Technology, New Taipei City 24301, Taiwan

\begin{abstract}
In this study, we used a hot-pressing process to enhance the photocatalytic properties of $\mathrm{TiO}_{2} / \mathrm{Fe}_{2} \mathrm{O}_{3}$ bimetallic oxide with a periodic patterned structure on the surface to increase photon absorption for photocatalysis in the oxygen evolution reaction (OER) for water splitting. The hot-pressed samples show that combining the two metal oxides improves the absorption band edge of the electrode at different wavelengths. The patterned structure obtained using the hot-pressing process successfully improves photon absorption, resulting in a two-fold enhancement compared with a flat surface electrode.
\end{abstract}

Keywords: bimetallic oxide, periodic pattern, hot-pressing process, water splitting

\section{Introduction}

Photocatalytic decomposition for water splitting to produce oxygen is a widely studied light energy conversion system $[1,2]$. When photons of different wavelengths are irradiated onto a semiconductor photocatalyst, their energy agitates its valence band electrons, making them jump to the conduction band. A photo-generated hole is formed in the valence band, and the excited electrons in the conduction band undergo a reduction reaction with water molecules to produce hydrogen via the so-called hydrogen evolution reaction (HER) [3]. This hole dominates oxygen production via the so-called oxygen evolution reaction (OER) [4]. The edge of the conduction band of the semiconductor photocatalyst material must be above the $\mathrm{H}^{+} / \mathrm{H}_{2}$ reduction energy level. The photoelectrons in the photocatalyst can reduce water to hydrogen. However, because the oxidation-reduction potential difference of the water-splitting reaction is $1.23 \mathrm{eV}$, the valence band energy level of the photocatalyst must be below the oxidation energy level of $\mathrm{O}_{2} / \mathrm{H}_{2} \mathrm{O}$ to oxidize water to oxygen.

To achieve this goal, the adjustment of the required energy and the coordination of the solar radiation spectrum is important [1]. Most previous studies have used noble metals such as Pt and Au as catalysts [2-5]; however, these are expensive and scarce, and therefore, studies have been conducted to find alternative catalytic materials. In this regard, typical semiconductor metal oxides have attracted much attention. Abundant metal oxides such as titanium dioxide $\left(\mathrm{TiO}_{2}\right)[6,7], \mathrm{WO}_{3}[8,9], \mathrm{BiVO}_{4}[10,11], \mathrm{CuO}_{2}[12,13]$, and ferric oxide $\left(\mathrm{Fe}_{2} \mathrm{O}_{3}\right)[14,15]$ enhance photon absorption through their $\mathrm{n}$ - or $\mathrm{p}$-type semiconductor properties and 
energy gap matching; therefore, they show high photocatalytic efficiency over a large wavelength range. The photon energy of a specific wavelength can cause the separation of electron-hole pairs, further promoting the conversion of light energy into chemical energy. $\mathrm{TiO}_{2}[16,17]$ and $\mathrm{Fe}_{2} \mathrm{O}_{3}[18,19]$ are commonly used for photocatalysis because they afford advantages such as simple preparation, high chemical stability, low cost, nontoxicity, and corrosion resistance; further, the energy gap of $\mathrm{TiO}_{2}(3.2 \mathrm{eV})$ shows good agreement with to the energy gap $(2.2 \mathrm{eV})$ of $\mathrm{Fe}_{2} \mathrm{O}_{3}[20,21]$, as shown in Fig. 1a. This property allows the bimetallic semiconductor formed by combining these two metal oxides to absorb more than $30 \%$ of the band gap effectively. Sunlight [22] can effectively enhance the photocatalytic effect of the electrode.

The dimensional structure of the electrode surface also influences the photoelectrochemical properties. In particular, periodic microstructures have attracted much interest in the field of optics. Yablonovitch and John described this concept in 1987 [23]. They aimed to design a medium that can capture photons to reduce energy consumption and waste. Through several years of research, they found that a medium with a particular periodic structure on the surface effectively traps photons [24,25] without changing the intrinsic chemical properties of matter to obtain the required optical properties. Thus far, many studies on solar energy have selected materials with periodic structures to increase photon energy absorption [26, 27]. Further, because a periodic microstructure drastically increases the reaction area of the electrode surface, the current response obtained will also be significantly improved.

In this study, we fabricated a simple pattern using a hot-pressing process onto the photoanode surface, as shown in Fig. 1b, and used an etching method to form an original substrate with a periodic surface structure. The original substrate is remolded by a polymer to serve as a new stamp substrate that is then used as a mold with the prepared layer of the $\mathrm{TiO}_{2} / \mathrm{Fe}_{2} \mathrm{O}_{3}$ cocatalyst. Finally, a hot-pressing process is performed to obtain a periodic microstructure. This process improves the carrier transfer rate through improved interface contact within the cocatalyst material and improves light absorption efficiency through additional light trapping and scattering from the surface patterns.

(a)

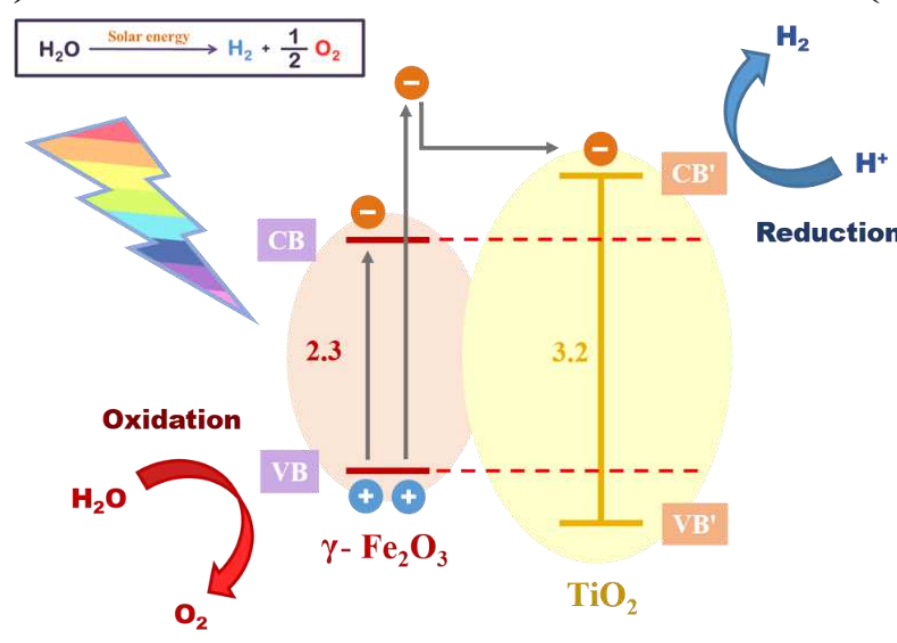

(b)

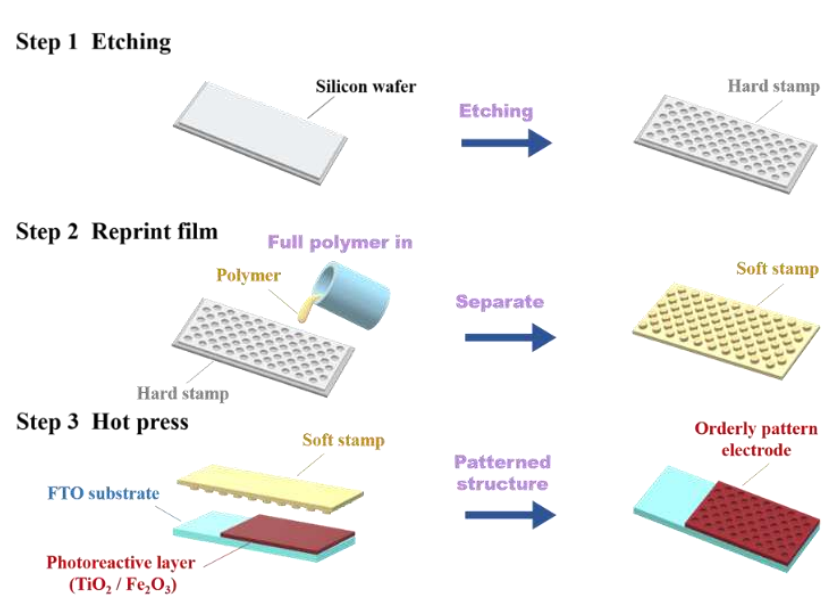

Figure 1. (a) Water-splitting reaction mechanism in $\mathrm{TiO}_{2} / \mathrm{Fe}_{2} \mathrm{O}_{3}$ bimetallic semiconductor system. (b) Fabrication of pattern using hot-pressing process.

\section{Experiments}

$\mathrm{FeCl}_{2}$ and $\mathrm{FeCl}_{3}$ were dissolved in deionized water, stirred to form a solution, quickly poured into a sodium hydroxide solution, and finally stirred at $80^{\circ} \mathrm{C}$ for $30 \mathrm{~min}$. After the solution was thoroughly mixed, it 
was left to stand for 30 min until the product precipitated. The upper layer solution was removed; the precipitate was washed with acetone, ethanol, and deionized water; and it was dried at $120^{\circ} \mathrm{C}$ for $12 \mathrm{~h}$ to obtain $\mathrm{Fe}_{3} \mathrm{O}_{4}$ (black powder). This powder was dissolved in alcohol and stirred vigorously for 30 min to obtain a reddish-brown $\mathrm{Fe}_{2} \mathrm{O}_{3}$ suspension solution. Finally, the precipitated $\mathrm{Fe}_{2} \mathrm{O}_{3}$ was placed in a quartz boat that in turn was placed in a sintering furnace at $450^{\circ} \mathrm{C}$ for $3 \mathrm{~h}$ and then cooled to room temperature naturally to obtain $\mathrm{Fe}_{2} \mathrm{O}_{3}$ powder with a hematite phase. $\mathrm{A} \mathrm{TiO}$ precursor solution was obtained by the addition of tetraethyl titanic acid to n-propanol to prepare a precursor solution followed by the addition of sulfuric acid and stirring at room temperature, allowing it stand to at $25^{\circ} \mathrm{C}$ for $2 \mathrm{~h}$ to form a translucent gel, placing in an oven at $50^{\circ} \mathrm{C}$, reheating it, and naturally cooling it to room temperature.

Finally, we prepared $7 \mathrm{wt} \%$ polyvinyl alcohol (PVA), added $1 \mathrm{~mL}$ of deionized water, and placed it on a hot plate at $120^{\circ} \mathrm{C}$ for $30 \mathrm{~min}$. Then, we stirred the PVA to make it effectively dissolve in deionized water to obtain solution A. We prepared $20 \mathrm{mg}$ of $\mathrm{Fe}_{2} \mathrm{O}_{3}$ powder and $98 \mu \mathrm{L}$ of $\mathrm{TiO}_{2}$ solution to dissolve in $1 \mathrm{~mL}$ of $\mathrm{N}-$ methyl-2-pyrrolidone (NMP), placed it in an ultrasonic oscillator, shook it for $30 \mathrm{~min}$ to obtain fixed solutions, and placed them in an ultrasonic oscillator for $30 \mathrm{~min}$ to obtain the final semiconductor bimetallic oxide colloidal solution. To prepare the soft stamp, we first used acetone, ethanol, and water to vibrate the silicon wafer after the 20 -min etching process to clean the board and then placed it on a heating plate at $40^{\circ} \mathrm{C}$ for drying. Simultaneously, the epoxy resin was activated and then laid flat on the original substrate surface until it dried. After drying, the epoxy resin was torn off from the original substrate to obtain the required soft stamp. We applied $100 \mu \mathrm{L}$ of the semiconductor bimetallic oxide colloidal solution to the $\mathrm{TiO}_{2}$ film surface and kept it at room temperature for $1 \mathrm{~h}$ until the colloidal solution changed to a jelly-like state, and then, we performed the hot-pressing process for $15 \mathrm{~min}$. Finally, the patterned photoanode was placed in a sintering furnace at $500^{\circ} \mathrm{C}$ for $3 \mathrm{~h}$ in an argon atmosphere to obtain the patterned photoanode with a periodic structure. The OER performance of the photoanode was examined using the three-electrode connection method. The system included the working electrodes, a counter electrode (carbon rod), and a reference electrode $(\mathrm{Ag} / \mathrm{AgCl})$ in 1 $\mathrm{M} \mathrm{KOH}$ as the electrolyte.

\section{Results and Discussion}

The surface-patterned structure was verified as shown in Fig. 2. Figure 2a shows a scanning electron microscope (SEM) image of the silicon wafer as a mother mold substrate. The surface had periodically arranged circular holes, each having an elongated $2-\mu \mathrm{m}$ aperture. Figure $2 \mathrm{~b}$ shows an image of the corresponding inverse pattern on the epoxy resin surface. The epoxy resin successfully replicated the whole structure from the original pattern of the Si substrate, which correspondingly showed periodically arranged cylindrical structures with a diameter of $2 \mu \mathrm{m}$. Finally, we examined whether the corresponding patterned periodic structure is transferred to the electrode surface via the hot-pressing process. Figure $2 \mathrm{c}$ shows the patterned $\mathrm{TiO}_{2} / \mathrm{Fe}_{2} \mathrm{O}_{3}$ photoanode before and after visible light irradiation. This figure shows that the electrode surface looks black when it is not illuminated. However, it shows a noticeable rainbow color under visible light irradiation, implying that the incident light is significantly trapped and refracted many times in the periodic patterned structure. Figure $2 \mathrm{~d}-\mathrm{e}$ presents SEM images of the surface of a patterned $\mathrm{TiO}_{2} / \mathrm{Fe}_{2} \mathrm{O}_{3}$ photoanode under different magnifications and angles. The photoelectrode surface exhibited a cycle similar to that of a silicon wafer motherboard. The pore size was approximately $2 \mu \mathrm{m}$, confirming that we successfully imprinted periodically patterned microstructures on the electrode surface. Finally, Fig. $2 \mathrm{f}$ presents a cross- 
sectional image produced by cutting the electrode surface using a focused ion beam (FIB). The cross-sectional image also shows the circular hole shape of this periodic patterned structure, with the hole depth being 0.642 $\mu \mathrm{m}$.

(a)

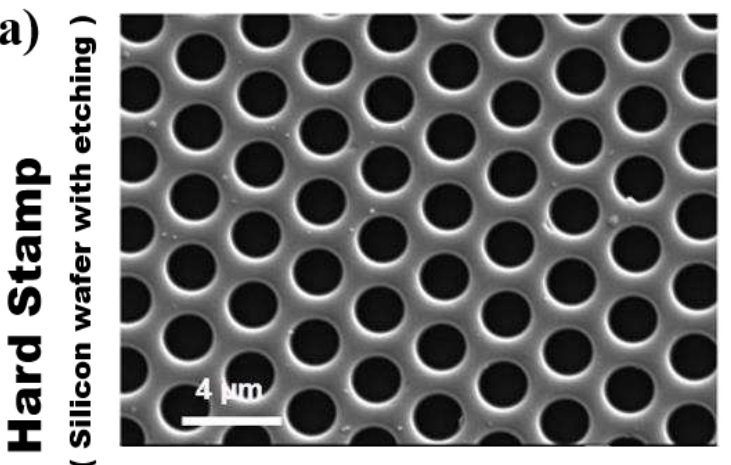

(b)

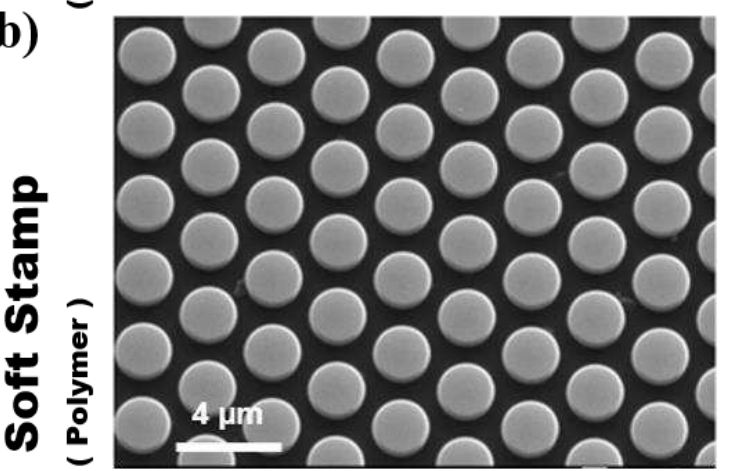

(c)
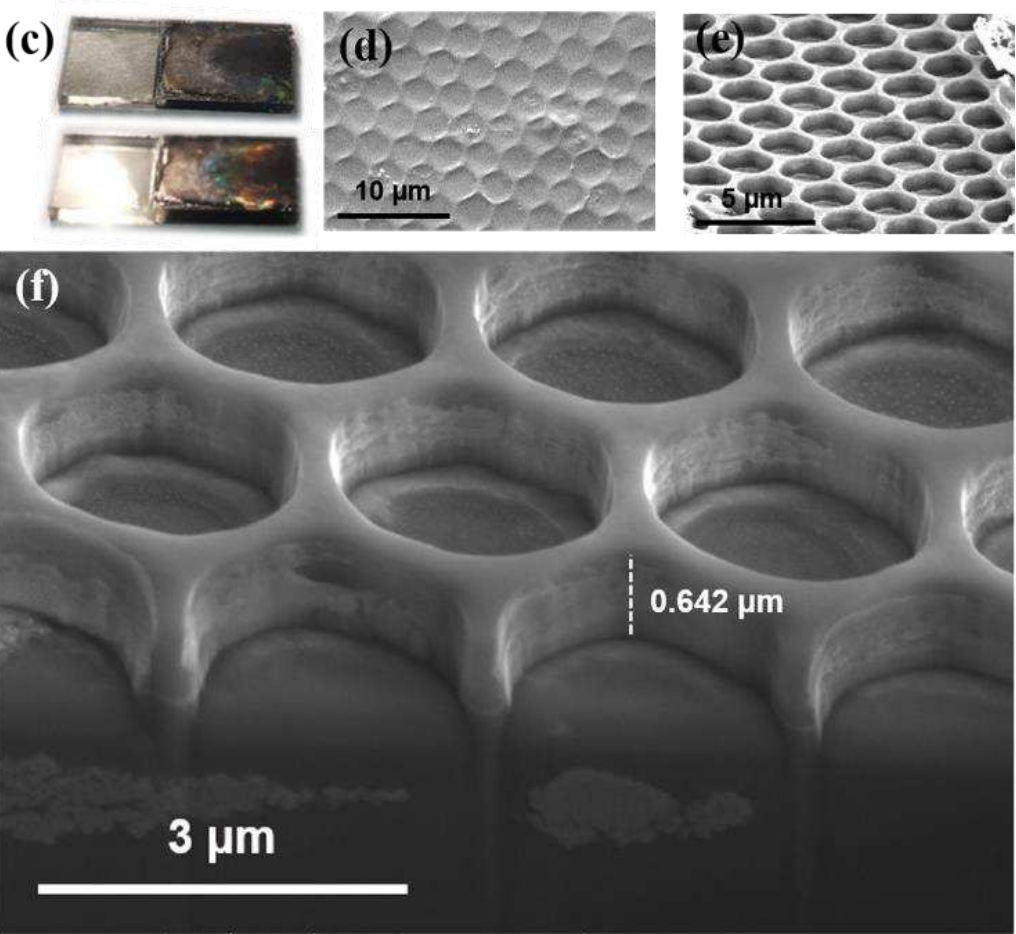

Figure 2. (a) SEM image of silicon wafer prepared using etching method. (b) Soft stamp made using silicon wafer with inverse pillar structure. (c) Photos captured with and without light irradiation. (d-e) SEM image under different magnifications and angles. (f) Cross-sectional image of electrode surface of $\mathrm{TiO}_{2} / \mathrm{Fe}_{2} \mathrm{O}_{3}$ ordered patterned photoanode.

To characterize the proposed $\mathrm{TiO}_{2} / \mathrm{Fe}_{2} \mathrm{O}_{3}$ patterned photoanode, we conducted FIB-transmission electron microscope (TEM) analysis. Figure 3a presents the result of the element distribution analysis (EDS mapping) of the $\mathrm{TiO}_{2} / \mathrm{Fe}_{2} \mathrm{O}_{3}$ patterned photoanode. $\mathrm{Fe}$, Ti, and $\mathrm{O}$ were uniformly distributed in the electrode, and the $\mathrm{C}$ signal arose from the PVA and NMP binders; however, this did not affect the distribution of the primary materials, namely $\mathrm{TiO}_{2}$ and $\mathrm{Fe}_{2} \mathrm{O}_{3}$. Figure $3 b$ presents STEM images obtained under different magnifications. $\mathrm{TiO}_{2}$ and $\mathrm{Fe}_{2} \mathrm{O}_{3}$ powders exhibited granular morphologies. As shown in Fig. 3c, the lattice parameters of $\mathrm{Fe}_{2} \mathrm{O}_{3}$ and $\mathrm{TiO}_{2}$ were determined through the analysis to be 0.28 and $0.31 \mathrm{~nm}$, respectively, indicating that the hotpressing process created lattice distortion in both $\mathrm{Fe}_{2} \mathrm{O}_{3}$ and $\mathrm{TiO}_{2}$. 

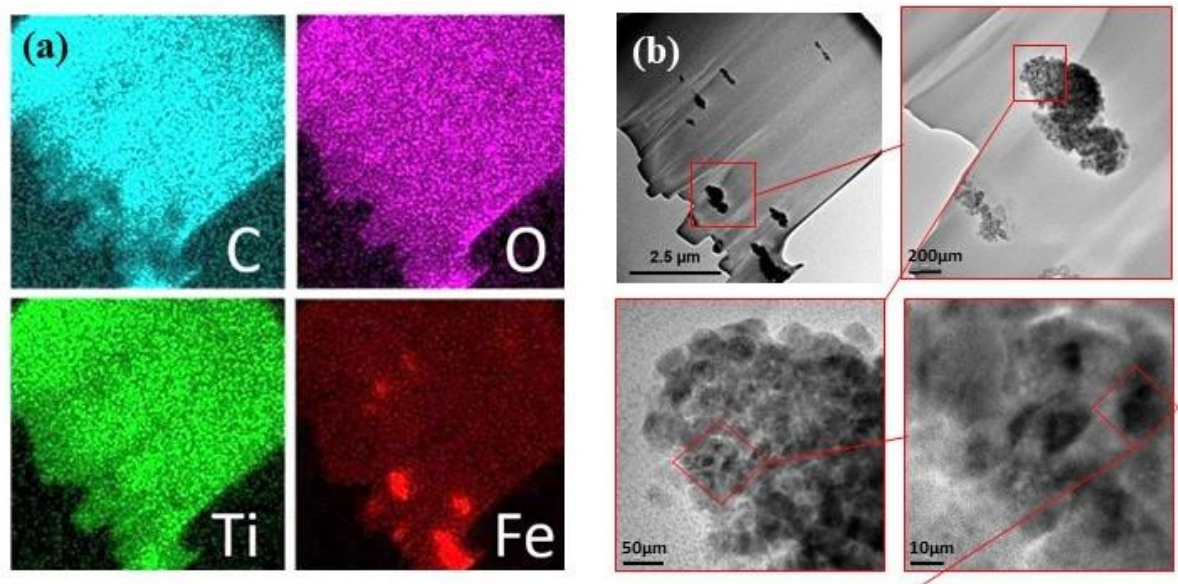

(c)
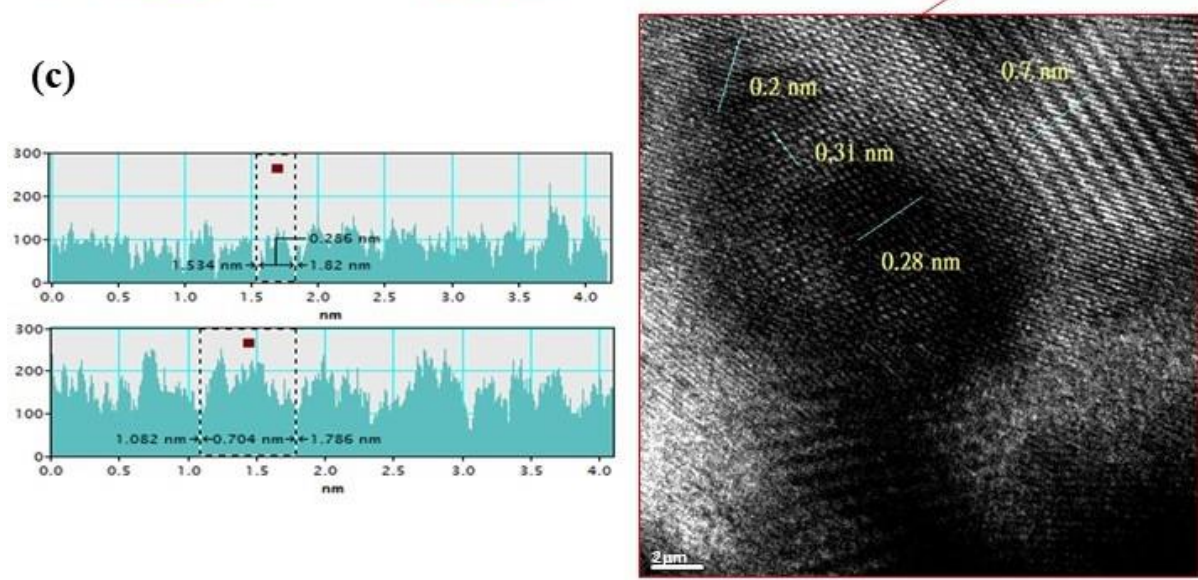

Figure 3. FIB-TEM image of $\mathrm{TiO}_{2} / \mathrm{Fe}_{2} \mathrm{O}_{3}$-ordered patterned photoanode with (a) EDS mapping of $\mathrm{C}$, $\mathrm{O}$, Ti, and Fe. (b) STEM images with different magnifications. (c) Analysis of $\mathrm{Fe}_{2} \mathrm{O}_{3}$ and $\mathrm{TiO}_{2}$ lattices.

Furthermore, we performed X-ray photoelectron spectroscopy (XPS) to determine the chemical states of elements. Figure 4 presents the results of the fine scan spectrum analysis performed using XPS for the six elements in the photoanode. In Fig. $4 \mathrm{a}$, the $\mathrm{C} 1 \mathrm{~s}$ orbital shows signals corresponding to a $\mathrm{C}-\mathrm{C}$ single bond and a C-O single bond at a binding energy of 284.9 eV. In Fig. 4b, the $\mathrm{O} 1 \mathrm{~s}$ orbital shows a signal of the $\mathrm{C}=\mathrm{O}$ double bond at a binding energy of $532.5 \mathrm{eV}$, confirming that many oxidized carbons exist on the electrode surface and a signal of the $\mathrm{O}$ from the oxides at a binding energy of $530 \mathrm{eV}$. In Fig. 4c, the $\mathrm{N}$ 1s orbital shows signals of the N-H bond at binding energies of 397.2 and $400 \mathrm{eV}$. The bonding $\mathrm{N}$ and metal ion may result from the bond between $\mathrm{N}$ and a small amount of transition metal elements is also seen. In Fig. $4 \mathrm{~d}, \mathrm{Fe} 2 \mathrm{p}_{2 / 3}$ and $\mathrm{Fe} 2 \mathrm{p}_{1 / 3}$ signals are seen at binding energies of 711.3 and $724.8 \mathrm{eV}$, respectively, and satellite peaks of Fe $2 \mathrm{p}_{2 / 3}$ and $\mathrm{Fe} 2 \mathrm{p}_{1 / 3}$ are seen at binding energies of 720 and $731.3 \mathrm{eV}$, respectively; these are typical $\mathrm{Fe}_{2} \mathrm{O}_{3}$ configuration signals. In Fig. $4 \mathrm{e}, \mathrm{Ti} 2 \mathrm{p}_{3 / 2}$ and Ti $2 \mathrm{p}_{1 / 2}$ signals are seen at binding energies of 457.9 and 464.3 $\mathrm{eV}$, respectively; these are generated by $\mathrm{TiO}_{2}$. In Fig. $4 \mathrm{f}, \mathrm{Sn} 3 \mathrm{~d}_{3 / 2}$ and $\mathrm{Sn} 3 \mathrm{~d}_{5 / 2}$ signals are seen at binding energies of 285.9 and $495.1 \mathrm{eV}$, respectively; these are generated by the $\mathrm{SnO}_{2}$ substrate. 
(a.)

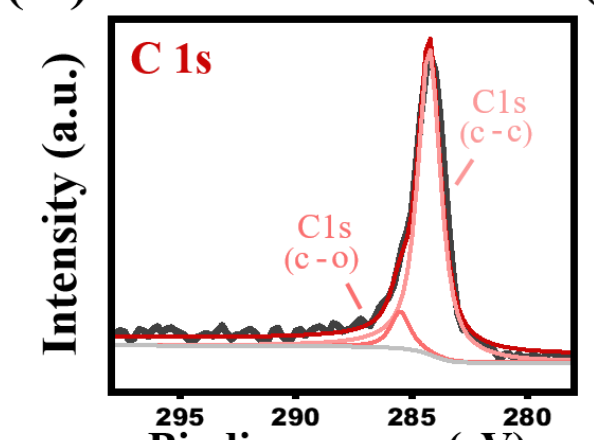

(d.)

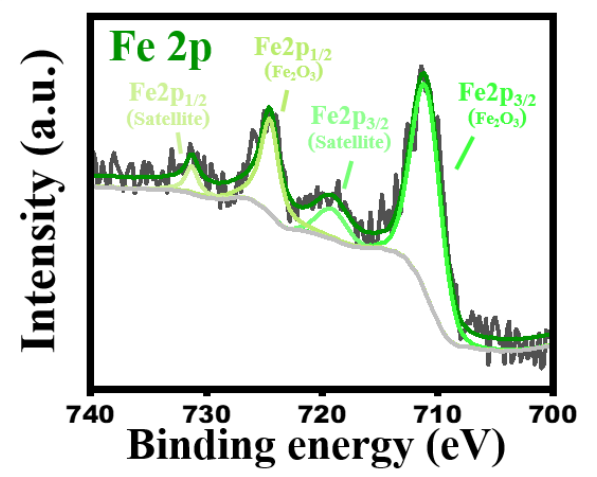

(b.)

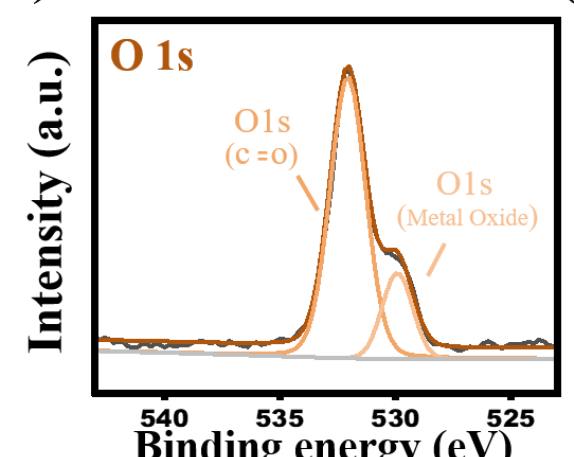

(e.)

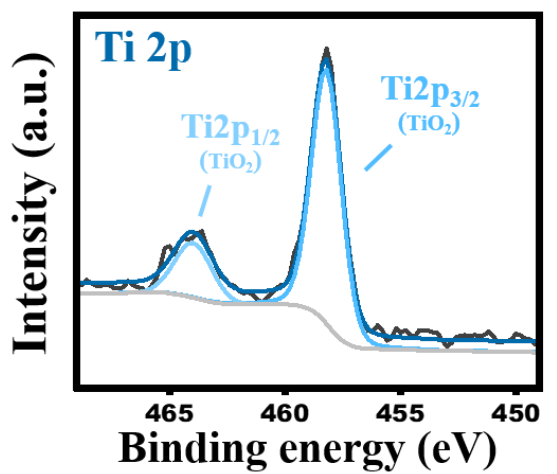

(c.)

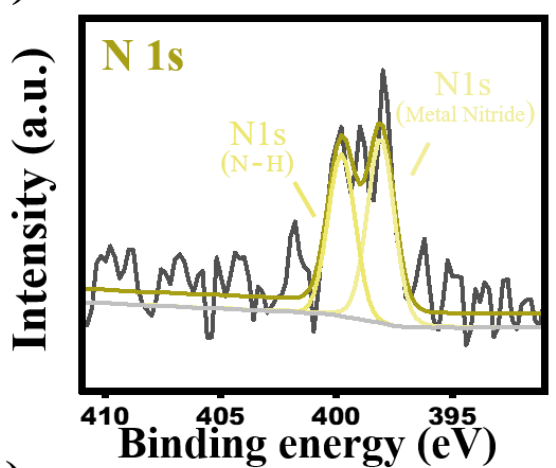

(f.)

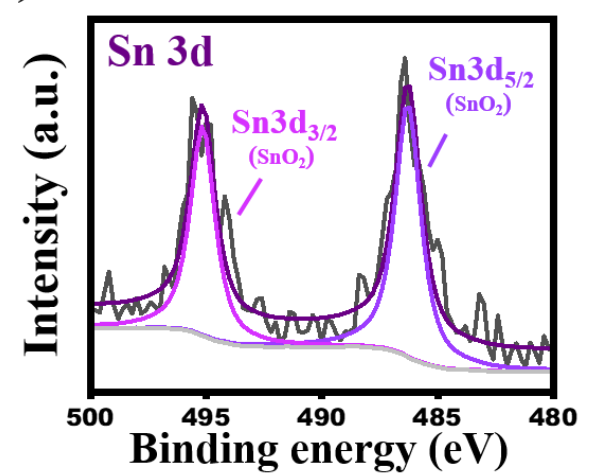

Figure 4. XPS spectra of $\mathrm{TiO}_{2} / \mathrm{Fe}_{2} \mathrm{O}_{3}$-ordered patterned photoanode for (a) $\mathrm{C} 1 \mathrm{~s}$, (b) $\mathrm{O} 1 \mathrm{~s}$, (c) $\mathrm{N} 1 \mathrm{~s}$, (d) Fe 2p, (e) Ti 2p, and (f) Sn 3d.

To demonstrate the effect of patterned structures on the light absorption of the photoanode, we performed ultraviolet-visible spectroscopy (UV-vis) before and after the hot-pressing process, as shown in Fig. 5a. Owing to the cocatalyst effect of the $\mathrm{TiO}_{2}$ and $\mathrm{Fe}_{2} \mathrm{O}_{3}$ metal oxides, the photoanode demonstrated light absorption over a broad range of 400-600 $\mathrm{nm}$. Compared with the electrode before the patterning process, the photoanode exhibited additional light absorption owing to enhanced light scattering and absorption from the periodic patterned structure on the surface. This enhancement is also reflected in the linear scanning voltammetry (LSV) shown in Fig. 5b; the $\mathrm{TiO}_{2} / \mathrm{Fe}_{2} \mathrm{O}_{3}$ sample produced using the hot-pressing process exhibited the highest reaction current during the LSV scan. Further, we performed a photoresponse study under zero bias and white light irradiation, and this sample showed two-fold improvement compared with the $\mathrm{TiO}_{2} / \mathrm{Fe}_{2} \mathrm{O}_{3}$ sample produced without using the hot-pressing process and seven-fold current improvement compared with $\mathrm{TiO}_{2}$ only, as shown in Fig. 5c. 

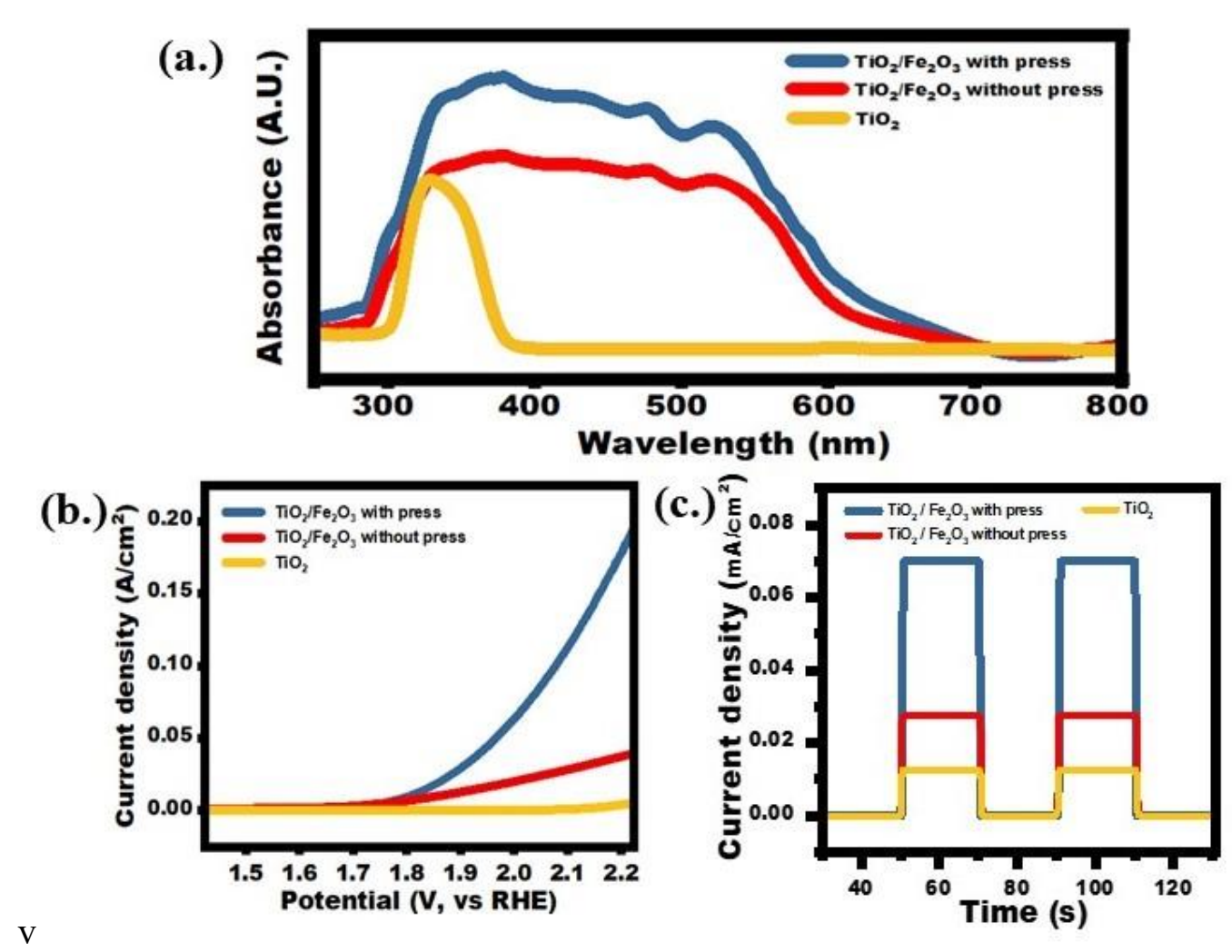

Figure 5. (a) UV-vis absorption spectra. (b) LSV swipe scan. (c) Photoresponses of different photoanodes.

\section{Conclusion}

In this study, we demonstrated a simple hot-pressing process to fabricate a periodic pattern on a $\mathrm{TiO}_{2} / \mathrm{Fe}_{2} \mathrm{O}_{3}$ cocatalyst bimetallic oxide photoanode. A clear periodic pattern of holes was reproduced on the photoanode surface. A broadband UV-vis absorption spectrum of the $\mathrm{TiO}_{2} / \mathrm{Fe}_{2} \mathrm{O}_{3}$ bimetallic oxide was obtained, and it showed light absorption over a broad range of $400-600 \mathrm{~nm}$. Finally, the $\mathrm{TiO}_{2} / \mathrm{Fe}_{2} \mathrm{O}_{3}$ cocatalyst with a patterned surface exhibited a significantly enhanced photocurrent owing to the additional light absorption and scattering from the surface structure.

\section{Acknowledgment}

This work was financially supported by the "High Entropy Materials Center" from The Featured Areas Research Center Program within the Higher Education Sprout Project framework of the Ministry of Education (MOE). We acknowledge the support from Project MOST 106-2221-E-008-106-MY3, 109-2634-F-007-024-, 108-2218-E-007-045-, 108-3116-F-008-008- (Dr. Wei-Hsuan Hung), 107-2218-E-131-004-MY3 and 1092221-E-131 -016 -MY3 (Dr. Chuan-Ming Tseng). 


\section{References}

1. Takata, T., et al., Photocatalytic water splitting with a quantum efficiency of almost unity. Nature, 2020. 581(7809): p. 411-414.

2. Maeda, K. and K. Domen, Photocatalytic water splitting: recent progress and future challenges. The Journal of Physical Chemistry Letters, 2010. 1(18): p. 2655-2661.

3. Mohammed-Ibrahim, J. and X. Sun, Recent progress on earth abundant electrocatalysts for hydrogen evolution reaction (HER) in alkaline medium to achieve efficient water splitting-A review. Journal of Energy Chemistry, 2019. 34: p. 111-160.

4. Tran, D.T., et al., Pt nanodots monolayer modified mesoporous Cu@ CuxO nanowires for improved overall water splitting reactivity. Nano Energy, 2019. 59: p. 216-228.

5. Wild, J. and L. McCready, Observations of the Spectrum of High-Intensity Solar Radiation at Metre Wavelengths. I. The Apparatus and Spectral Types of Solar Burst Observed. Australian Journal of Chemistry, 1950. 3(3): p. 387-398.

6. Yu, J., L. Qi, and M. Jaroniec, Hydrogen production by photocatalytic water splitting over Pt/TiO ${ }_{2}$ nanosheets with exposed (001) facets. The Journal of Physical Chemistry C, 2010. 114(30): p. 1311813125.

7. Galińska, A. and J. Walendziewski, Photocatalytic water splitting over Pt- TiO2 in the presence of sacrificial reagents. Energy \& Fuels, 2005. 19(3): p. 1143-1147.

8. Iwase, A., H. Kato, and A. Kudo, Nanosized Au particles as an efficient cocatalyst for photocatalytic overall water splitting. Catalysis Letters, 2006. 108(1-2): p. 7-10.

9. Chiarello, G.L., E. Selli, and L. Forni, Photocatalytic hydrogen production over flame spray pyrolysissynthesized $\mathrm{TiO}_{2}$ and $\mathrm{Au} / \mathrm{TiO}_{2}$. Applied Catalysis B: Environmental, 2008. 84(1-2): p. 332-339.

10. Kumar, S.G. and KK. Rao, Comparison of modification strategies towards enhanced charge carrier separation and photocatalytic degradation activity of metal oxide semiconductors $\left(\mathrm{TiO}_{2}, \mathrm{WO}_{3}\right.$ and ZnO). Applied Surface Science, 2017. 391: p. 124-148.

11. Habisreutinger, S.N., L. Schmidt-Mende, and J.K. Stolarczyk, Photocatalytic reduction of $\mathrm{CO}_{2} \mathrm{On} \mathrm{TiO}_{2}$ and other semiconductors. Angewandte Chemie International Edition, 2013. 52(29): p. 7372-7408.

12. Huang, T., et al., Photocatalytic activities of hetero-junction semiconductors $\mathrm{WO}_{3} / \mathrm{SrNb}_{2} \mathrm{O}_{6}$. Materials Science and Engineering: B, 2007. 141(1-2): p. 49-54.

13. Ma, J., et al., Pt nanoparticles sensitized ordered mesoporous WO3 semiconductor: gas sensing performance and mechanism study. Advanced Functional Materials, 2018. 28(6): p. 1705268.

14. Wang, Q., et al., Designing non-noble/semiconductor Bi/BiVO4 photoelectrode for the enhanced photoelectrochemical performance. Chemical Engineering Journal, 2017. 326: p. 411-418.

15. Tayebi, M. and B.-K. Lee, Recent advances in BiVO4 semiconductor materials for hydrogen production using photoelectrochemical water splitting. Renewable and Sustainable Energy Reviews, 2019. 111: p. 332-343.

16. Zhong, Y., et al., Direct visualization of ambipolar Mott transition in cuprate CuO2 planes. arXiv preprint arXiv:1904.12280, 2019.

17. Takagi, H., S. Uchida, and Y. Tokura, Superconductivity produced by electron doping in CuO 2-layered compounds. Physical review letters, 1989. 62(10): p. 1197.

18. Cherepy, N.J., et al., Ultrafast studies of photoexcited electron dynamics in $\gamma$-and $\alpha-\mathrm{Fe}_{2} \mathrm{O}_{3}$ 
semiconductor nanoparticles. The Journal of Physical Chemistry B, 1998. 102(5): p. 770-776.

19. Touba, S. and S. Kimiagar, Enhancement of sensitivity and selectivity of $\alpha-\mathrm{Fe}_{2} \mathrm{O}_{3}$ nanorod gas sensors by $\mathrm{ZnO}$ nanoparticles decoration. Materials Science in Semiconductor Processing, 2019. 102: p. 104603.

20. Ahmed, A.M., et al., Enhanced photoelectrochemical water splitting activity of carbon nanotubes@ $\mathrm{TiO}_{2}$ nanoribbons in different electrolytes. Chemosphere, 2020. 238: p. 124554.

21. Wang, G., et al., Hydrogen-treated $\mathrm{TiO}_{2}$ nanowire arrays for photoelectrochemical water splitting. Nano letters, 2011. 11(7): p. 3026-3033.

22. Sivula, K., F. Le Formal, and M. Grätzel, Solar water splitting: progress using hematite $\left(\alpha-\mathrm{Fe}_{2} \mathrm{O}_{3}\right)$ photoelectrodes. ChemSusChem, 2011. 4(4): p. 432-449.

23. Masoumi, Z., M. Tayebi, and B.-K. Lee, The role of doping molybdenum (Mo) and back-front side illumination in enhancing the charge separation of $\alpha-\mathrm{Fe}_{2} \mathrm{O}_{3}$ nanorod photoanode for solar water splitting. Solar Energy, 2020. 205: p. 126-134.

24. Fu, Y., et al., A ternary nanostructured $\alpha-\mathrm{Fe}_{2} \mathrm{O}_{3} / \mathrm{Au} / \mathrm{TiO} \mathrm{O}_{2}$ photoanode with reconstructed interfaces for efficient photoelectrocatalytic water splitting. Applied Catalysis B: Environmental, 2020. 260: p. 118206.

25. Bashiri, R., et al., HierarchicallySrTiO @ $\mathrm{TiO}_{2} @ \mathrm{Fe}_{2} \mathrm{O}_{3}$ nanorod heterostructures for enhanced photoelectrochemical water splitting. International Journal of Hydrogen Energy, 2020.

26. Li, Y., et al., Hierarchically branched $\mathrm{Fe}_{2} \mathrm{O}_{3} @ \mathrm{TiO}_{2}$ nanorod arrays for photoelectrochemical water splitting: facile synthesis and enhanced photoelectrochemical performance. Nanoscale, 2016. 8(21): p. 11284-11290.

27. Yablonovitch, E., Photonic crystals: semiconductors of light. Scientific American, 2001. 285(6): p. 4655.

28. Thongrattanasiri, S., F.H. Koppens, and FJG De Abajo, Complete optical absorption in periodically patterned graphene. Physical review letters, 2012. 108(4): p. 047401.

29. Dong, J., et al., Robust absorption broadband in one-dimensional metallic-dielectric quasi-periodic structure. Optics express, 2006. 14(5): p. 2014-2020.

30. Muhammad, M.H., M.F.O. Hameed, and S. Obayya, Broadband absorption enhancement in periodic structure plasmonic solar cell. Optical and Quantum Electronics, 2015. 47(6): p. 1487-1494.

31. Yang, L., et al., Metal nanoparticles influence on light absorbed power of thin-film solar cell with periodic structure. Optik, 2013. 124(14): p. 1921-1925. 
(a)

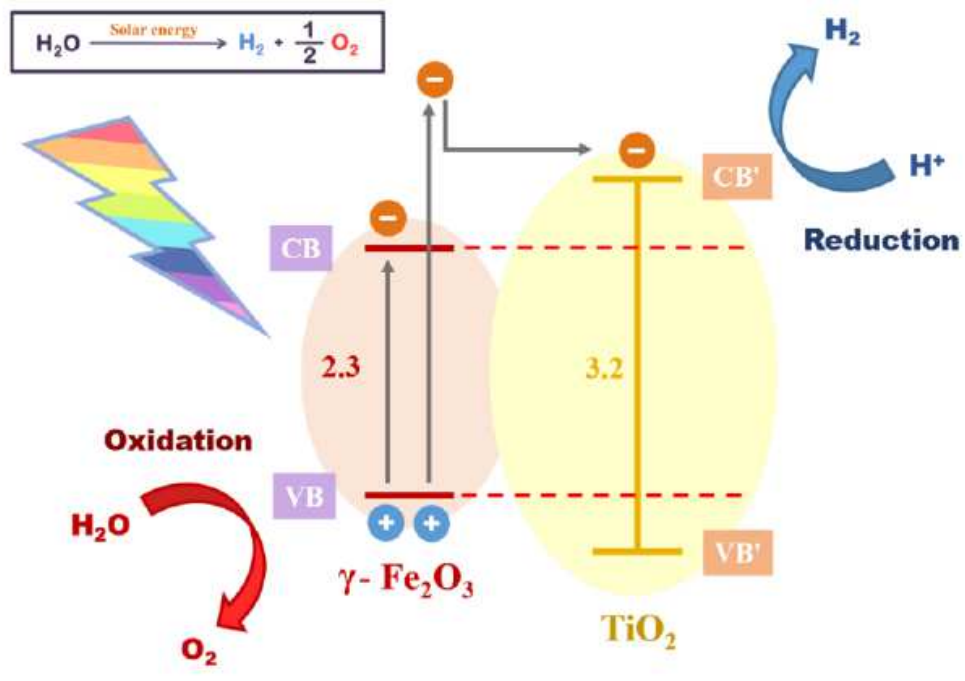

(b)

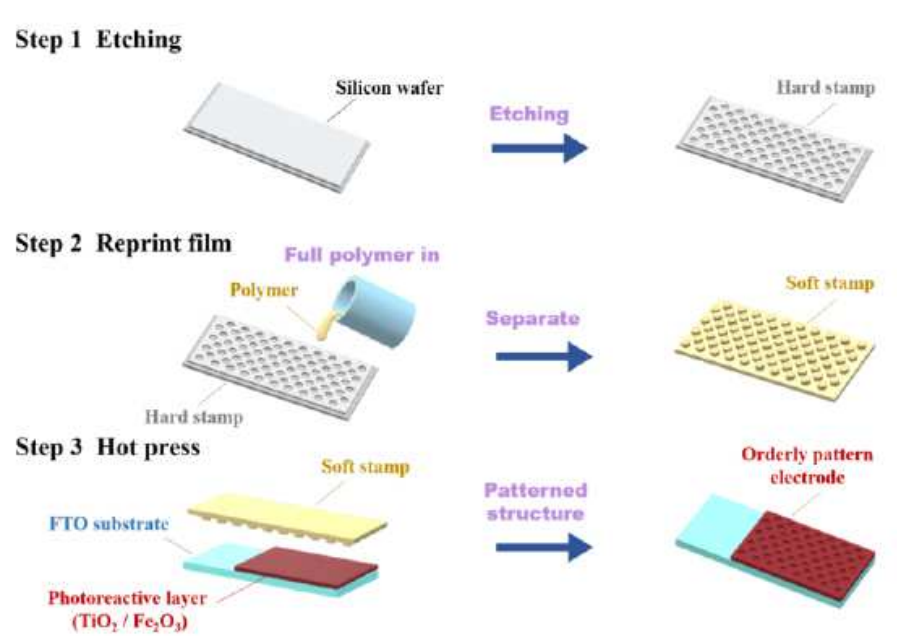

\section{Figure 1}

(a) Water-splitting reaction mechanism in $\mathrm{TiO} 2 / \mathrm{Fe} 2 \mathrm{O} 3$ bimetallic semiconductor system. (b) Fabrication of pattern using hot-pressing process.
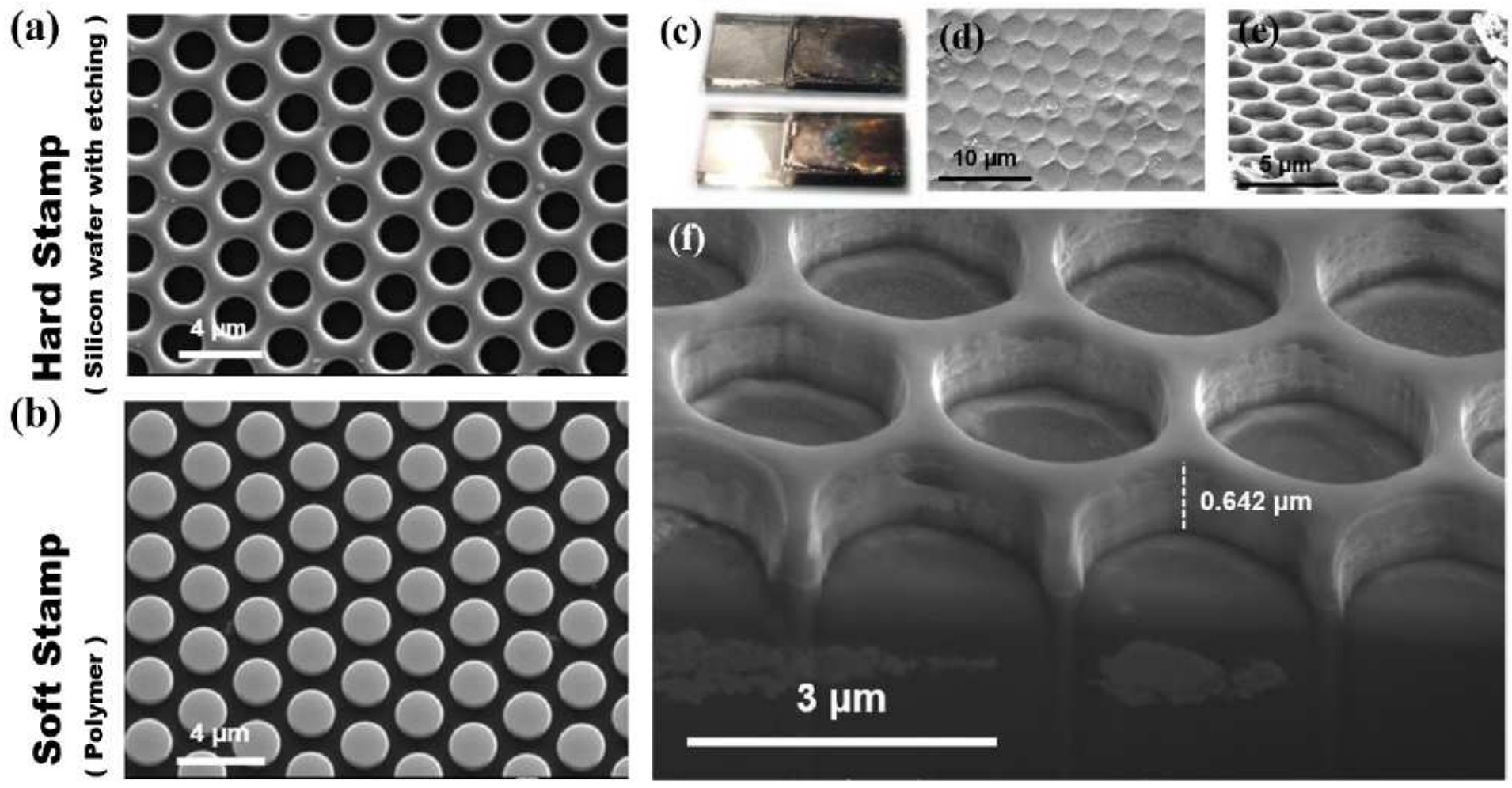

Figure 2

(a) SEM image of silicon wafer prepared using etching method. (b) Soft stamp made using silicon wafer with inverse pillar structure. (c) Photos captured with and without light irradiation. (d-e) SEM image 
under different magnifications and angles. (f) Cross-sectional image of electrode surface of TiO2/Fe2O3 ordered patterned photoanode.
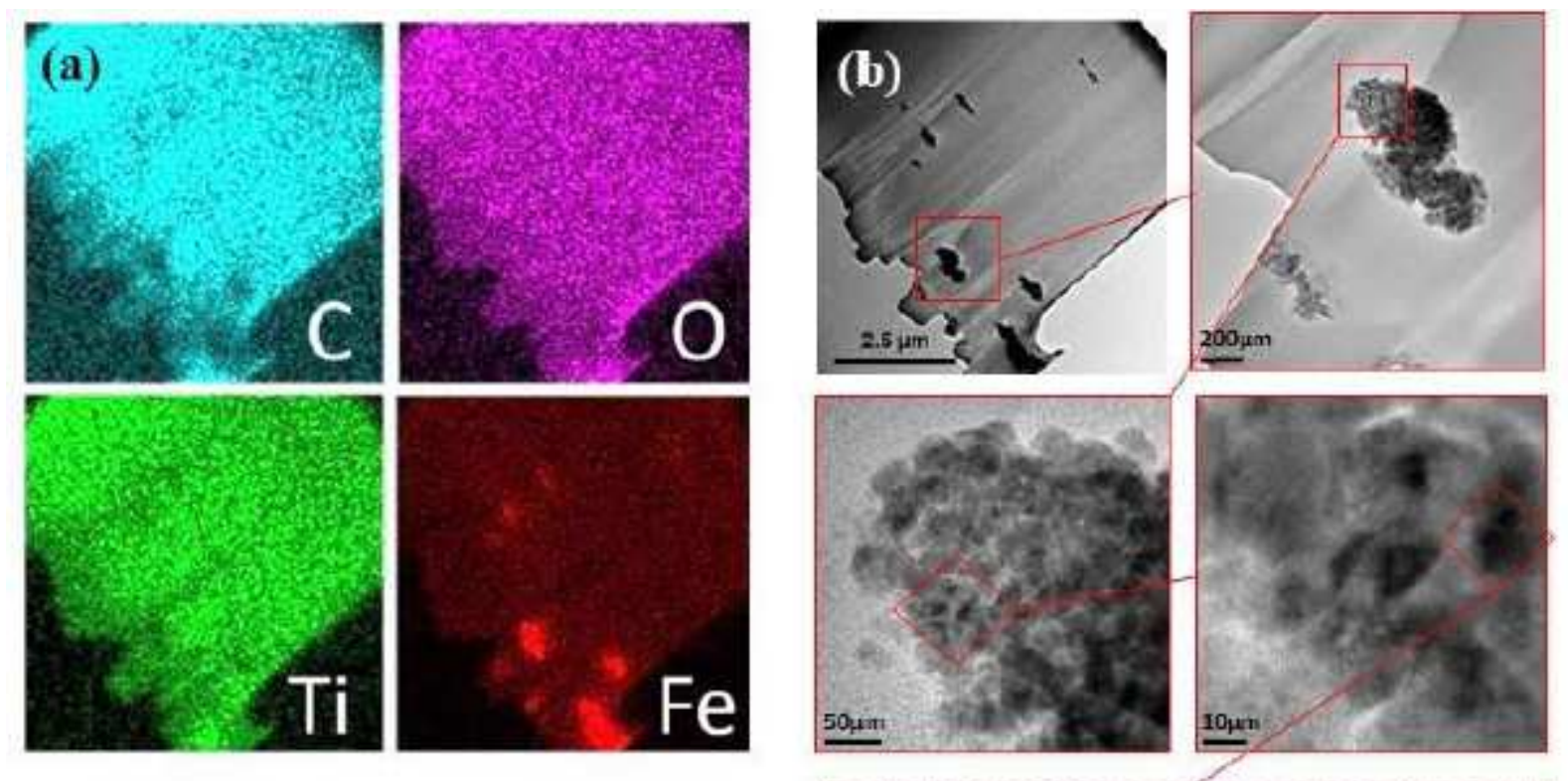

\section{(c)}
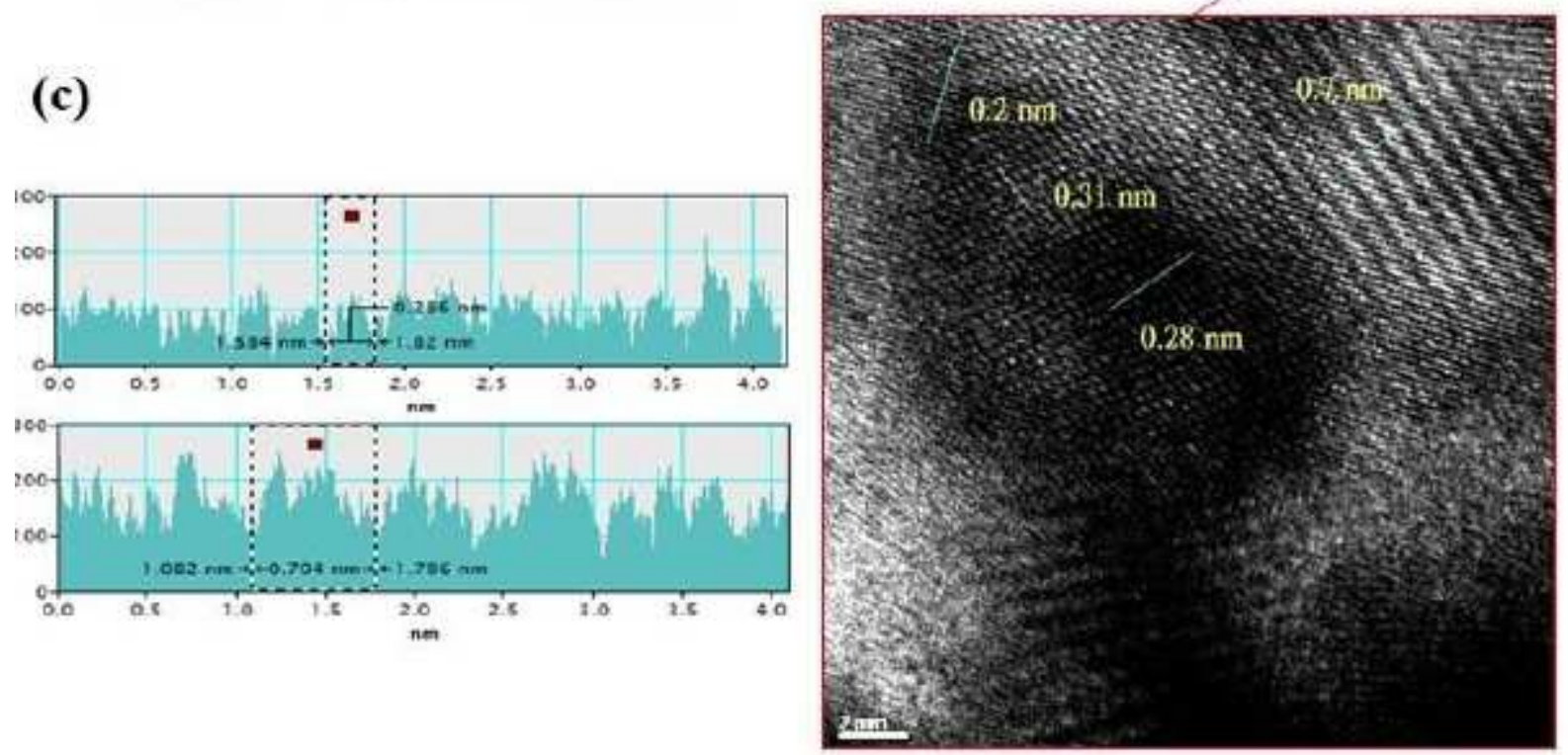

Figure 3

FIB-TEM image of TiO2/Fe2O3-ordered patterned photoanode with (a) EDS mapping of C, O, Ti, and Fe. (b) STEM images with different magnifications. (c) Analysis of Fe2O3 and TiO2 lattices. 
(a.)

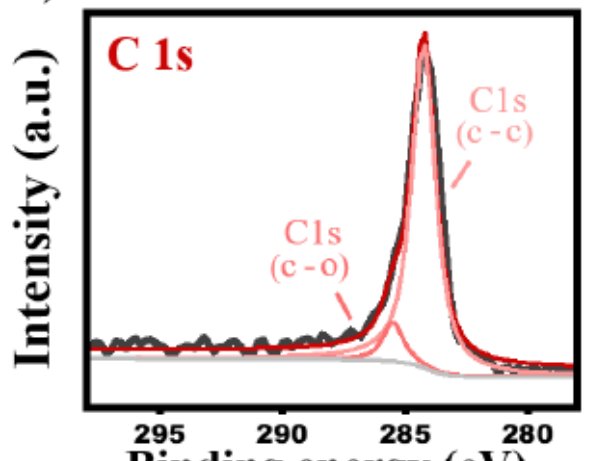

(d.)

Binding energy $(\mathrm{eV})$

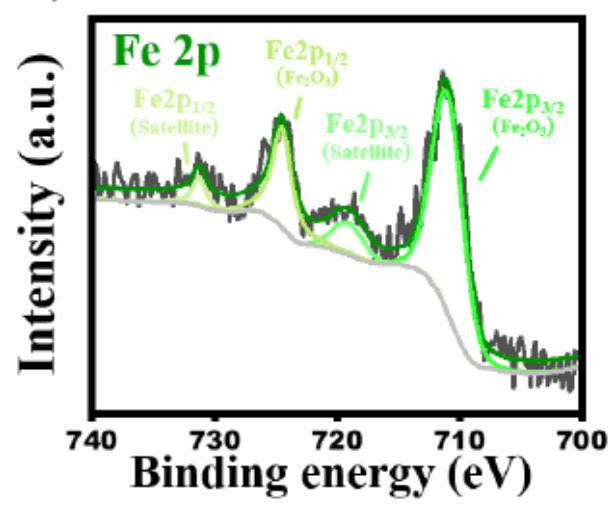

(b.)

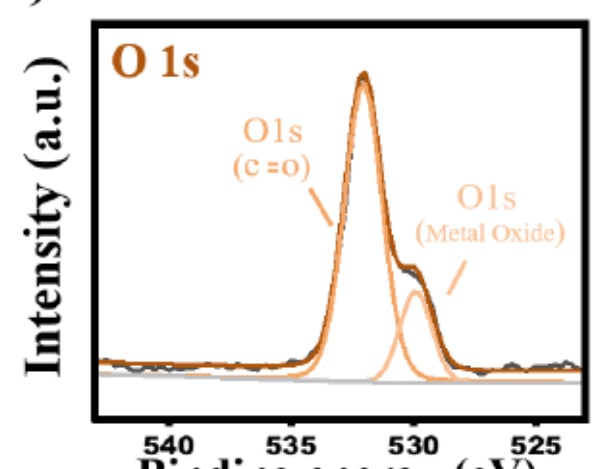

(e.)

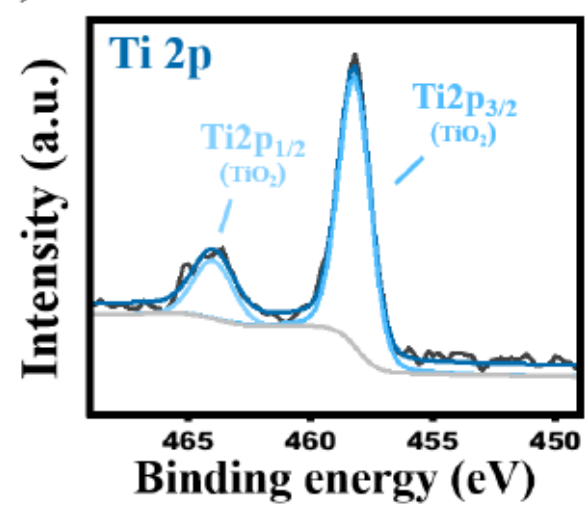

(c.)

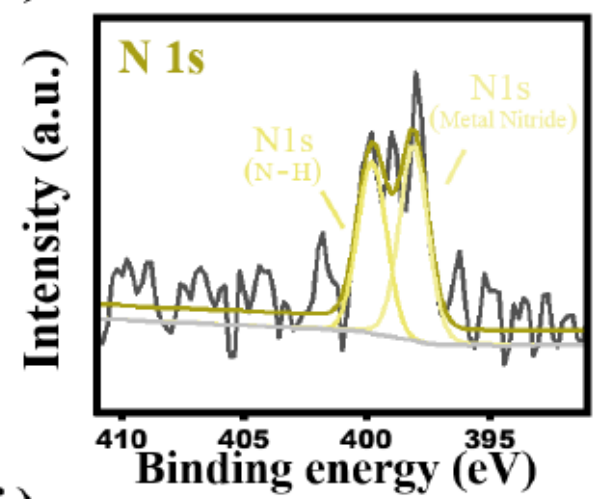

(f.)

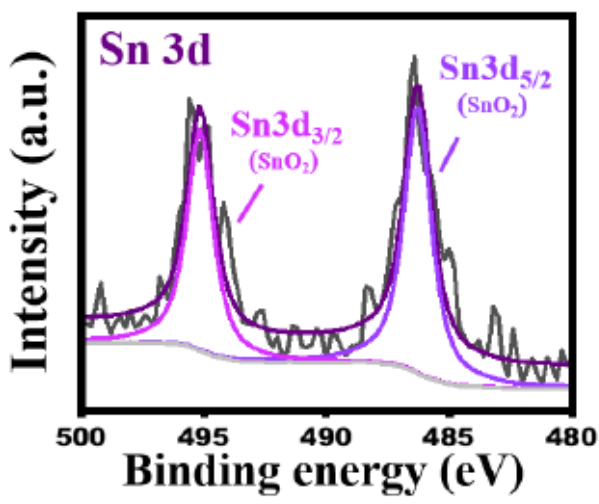

Figure 4

XPS spectra of TiO2/Fe2O3-ordered patterned photoanode for (a) C 1s, (b) 0 1s, (c) N 1s, (d) Fe 2p, (e) Ti $2 p$, and (f) Sn 3d. 

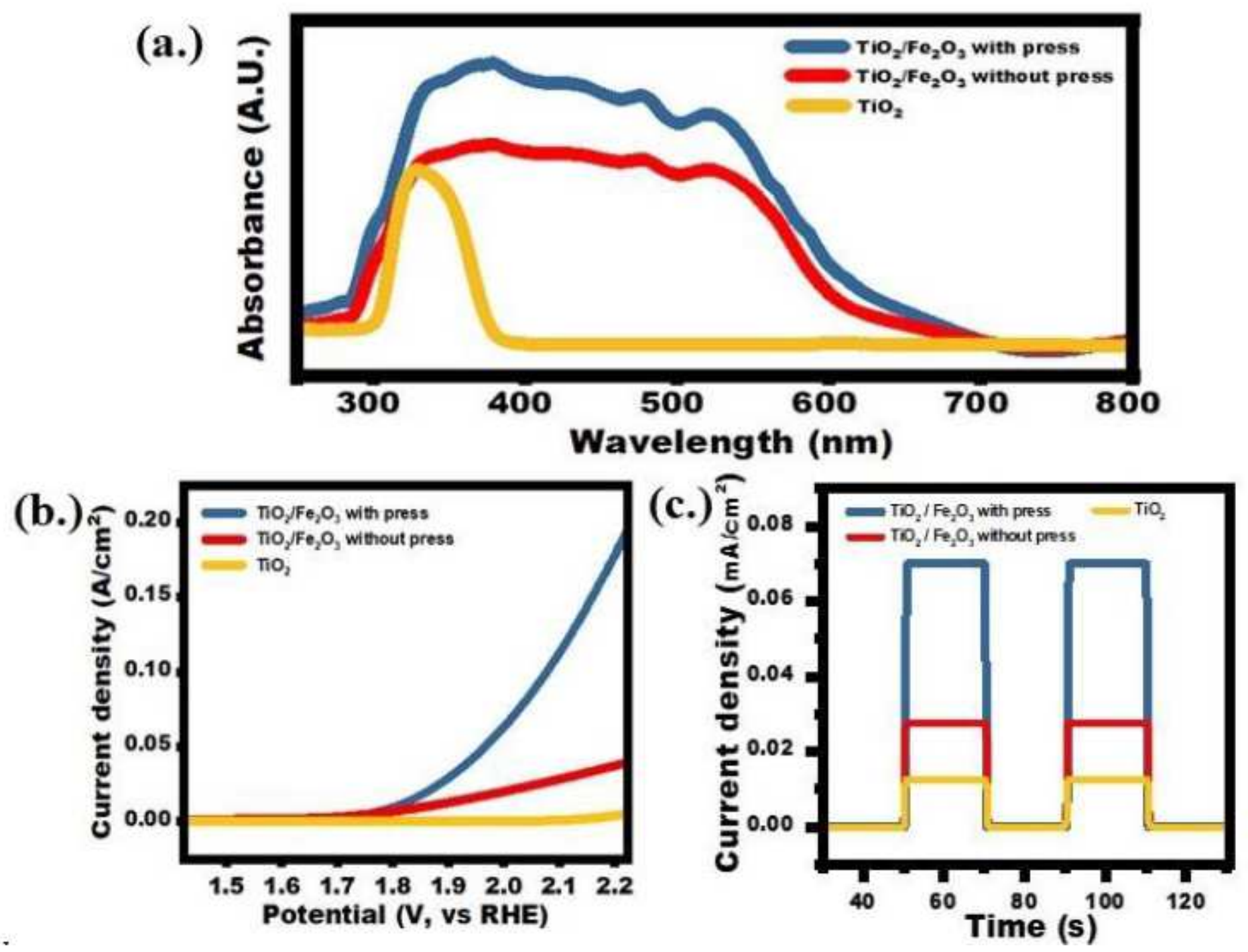

Figure 5

(a) UV-vis absorption spectra. (b) LSV swipe scan. (c) Photoresponses of different photoanodes. 